\title{
Sexual Orientation and Patient-Provider Communication About Sexual Problems or Concerns Among US Adults
}

\author{
Kathryn E. Flynn, $P h D^{7}$, Dane Whicker, $P h D^{2}$, Li Lin, $M S^{2}$, Rachel Cusatis, $P h D^{7}$, \\ Alan Nyitray, $P h D^{7}$, and Kevin $P$. Weinfurt, $P h D^{2}$
}

'Medical College of Wisconsin, Milwaukee, WI, USA; ${ }^{2}$ Duke University School of Medicine, Durham, NC, USA.

\begin{abstract}
BACKGROUND: Limited patient-provider communication about sexual health is a crucial barrier to patients receiving treatment for sexual problems, and little is known about how patient sexual orientation is associated with patient-provider communication about sexual problems. OBJECTIVE: To describe the prevalence of patientprovider communication about sexual problems and the associations between communication and (1) persistent sexual problems and (2) whether those who identified as lesbian, gay, or bisexual had disclosed their sexual orientation to their clinicians.
\end{abstract}

DESIGN: Cross-sectional, online survey

PARTICIPANTS: 4325 English-speaking US adults from KnowledgePanel $\AA$, a probability-based sample of the civilian, noninstitutionalized population.

MAIN MEASURES: Sexual orientation, disclosure of sexual orientation (being "out") to a health care provider, communication with health care providers regarding sexual problems or concerns, and persistent sexual problems or concerns.

KEY RESULTS: In the past year, 8-15\% of US adults discussed a sexual problem or concern with a health care provider. Between 23 and $42 \%$ of US adults reported persistent sexual problem(s) in the past year, and of those, $18 \%$ of gay/lesbian women, $20 \%$ of heterosexual women, $22 \%$ of bisexual women, $30 \%$ of gay men, $31 \%$ of heterosexual men, and $37 \%$ of bisexual men had discussed a sexual concern with a clinician. Eighty percent of gay/ lesbian women and $70 \%$ of gay men had disclosed their sexual orientation to their regular health care provider, versus only $24 \%$ of bisexual men and women. Among those who were "out," $30 \%$ had ever talked to a clinician about a sexual problem compared with $17 \%$ of those who were not "out." A smaller proportion of lesbian women had ever received care or treatment for a sexual problem, $6 \%$ compared with 14-23\% in the other groups.

CONCLUSIONS: There are significant unmet needs among US adults with regard to patient-provider communication about sexual problems or concerns. Improving patient-provider communication about sexual health is critical.

Electronic supplementary material The online version of this article (https://doi.org/10.1007/s11606-019-05300-3) contains supplementary material, which is available to authorized users.

Received November 28, 2018

Revised May 2, 2019

Accepted July 17, 2019

Published online August 26, 2019
KEY WORDS: communication; patient-centered care; doctor-patient relationships; men's health; women's health.

J Gen Intern Med 34(11):2505-11

DOI: $10.1007 / \mathrm{s} 11606-019-05300-3$

(c) Society of General Internal Medicine 2019

\section{INTRODUCTION}

Sexual health - both physical and psychosocial well-being in relation to sexuality - is an important component of quality of life for many adults. ${ }^{1}$ However, sexual problems are prevalent, including lack of interest, lack of enjoyment, difficulties with orgasm, pain, erectile difficulties (men), and lack of vaginal lubrication (women). ${ }^{2}$ There are effective therapies for addressing many sexual problems and concerns, ${ }^{3-6}$ but limited patient-provider communication is a crucial barrier to patients receiving such therapies.

Unmet needs in patient-provider communication about sex have been documented in many settings including primary care ${ }^{7}$ oncology care, ${ }^{8,9}$ cardiology care, ${ }^{10}$ and care for older women. ${ }^{11,12}$ Less is known about how patient sexual orientation is associated with patient-provider communication about sexual problems or concerns. One mixed methods study $(n=$ 124) highlighted additional barriers faced by gay and bisexual men regarding communication with their health care providers about sexual problems after prostate cancer. ${ }^{13}$ A large survey of Dutch adults $(n=4,333)$ found that sexual orientation was related to reporting a need for professional sexual health care, with more bisexual women (43\%) and gay men $(46 \%)$ reporting needs over the previous 12 months compared with heterosexual men (18\%) and women (27\%). ${ }^{14}$

When considering whether unmet needs differ by sexual orientation, disclosure of sexual orientation to health care providers is relevant. There are many factors that influence whether sexual minority patients choose to disclose their sexual orientation to clinicians. A recent systematic review of sexual orientation disclosure in health care among adults found 31 studies representing 2442 participants and concluded that the prominent barriers to disclosure were widespread but conducive to intervention - namely, perceived relevance of disclosure to care, the communication skills and language used by the health care provider, and fear of poor treatment or negative reaction after disclosure. ${ }^{15}$ For sexual minority 
patients, being "out" to a clinician may be a prerequisite to a candid and complete discussion of sexual health and/or sexual concerns.

A limitation of the existing literature is the heterogeneity of methods and measures across studies; thus, we lack a solid understanding of unmet needs in patient-provider communication about sexual problems, especially with regard to sexual orientation and disclosure of sexual orientation for sexual minority patients. Our recent work showed differences by gender and sexual orientation regarding sexual dysfunction, ${ }^{16}$ but it is not clear if the communication about these sexual problems differs by gender and/or sexual orientation. In this study, we estimated the prevalence of English-speaking US adults who discussed sexual problems or concerns with clinicians. We examined the associations between having discussed sexual problems or concerns with a clinician and (1) reporting persistent sexual problems or concerns and (2) whether those who identified as lesbian, gay, or bisexual were "out" to their clinicians.

\section{METHODS}

We surveyed participants through KnowledgePanel ${ }^{\circledR}$, an online panel of $\sim 55,000$ members, which provides a statistically valid representation of the US population through its use of address-based probability sampling, by providing internet access to panel members who do not have it, and by minimizing participant burden and attrition compared with opt-in panels. ${ }^{17}$ Data were collected in June 2013 from the general population of English-speaking adults $(n=3516)$, including 164 people who identified as lesbian, gay, or bisexual. In July 2014, we surveyed an additional sample of English-speaking adults who self-identified as lesbian, gay, or bisexual $(n=1011)$. Since both assessments drew from the same panel, it is possible that sexual minority respondents could have participated twice. Thus, for this analysis, we removed the 164 sexual minority respondents from the general population sample, for a total sample size of 4325 . We previously reported on the sexual activity status, sexual function, and sexual satisfaction among sexual minority and heterosexual adults using these data. ${ }^{16}$ The institutional review boards of the Duke University Health System and the Medical College of Wisconsin approved the studies, and participants provided consent online.

The questionnaire covered demographics, health, and sexual function. Question wording for key variables is provided in the Online Appendix. We did not include questions about gender identity and gender assignment at birth and thus were unable to determine the number of transgender respondents. The main outcome of interest, communication with health care providers regarding sexual problems or concerns, was measured with a question that we developed and pre-tested, which we previously used in a sample of patients with cancer. ${ }^{9} \mathrm{We}$ measured persistent sexual problems or concerns using a checklist-style screening item that we developed and tested in the general population, including heterosexual and sexual minority individuals. The first response option was "you had no interest in sex." There is debate about whether lack of interest in sex is necessarily a sexual problem, and during item evaluation, we modified it to "you wanted to feel more interest in sexual activity" in order to incorporate a sense of being bothered by low/no interest. ${ }^{18}$ However, the original item wording was administered in these surveys and thus for analysis in the current study, we considered a persistent problem to be endorsement of any of the listed response options except "you had no interest in sex" or "no problems or concerns."

We adjusted statistics for the complex survey sample design. Because the two samples have different survey weights, we made comparisons across the two samples by comparing the $95 \%$ confidence intervals around the point estimates. Nonoverlapping confidence intervals correspond to $p<0.01$ and are thus considered statistically significant. ${ }^{19}$ Within the sexual minority sample, we used Rao-Scott $\chi^{2}$ tests to test differences, e.g., to determine whether discussing sexual problems was associated with being "out" to a clinician. We hypothesized that being "out" was associated with discussing sexual problems with a clinician. We used SAS version 9.3 (SAS Institute Inc) and a 2-tailed significance level of $\alpha=.05$ for direct comparisons.

\section{RESULTS}

Using Response Rate 1 of the American Association for Public Opinion Research, screener and survey completion rates were $44 \%$ and $96 \%$ for the general population sample and $55 \%$ and $91 \%$ for the sexual minority sample, respectively. Because of survey weighting, demographic characteristics generally reflected the general population (Table 1). We noted that bisexual men and women were younger than gay/lesbian or heterosexual respondents.

\section{Patient-Provider Communication About Sexual Orientation}

Gay and lesbian participants were much more likely than bisexual participants to be "out" to their regular doctor or health care provider. Over half of gay men and lesbian women reported having discussed their sexual orientation with their regular doctor or health care provider, in contrast to the $46 \%$ of bisexual men and $36 \%$ of bisexual women who reported that they definitely had not discussed it (Table 2). After collapsing the two types of "yes" responses and the two types of "no" responses, $80 \%$ percent of lesbian women and $70 \%$ of gay men were "out" to their regular provider, compared with $24 \%$ of bisexual men and women (Fig. 1). A higher proportion of sexual minority participants who were married or in a relationship were "out" to their regular provider (54\%) compared with those who were single and not dating (43\%). 
Table 1 Characteristics of the Study Population by Self-reported Gender and Sexual Orientation (Percentages May Not Sum to 100 Because of Rounding and Weighting) $(n=4325)$

\begin{tabular}{|c|c|c|c|c|c|c|}
\hline \multirow[t]{2}{*}{ Characteristic } & \multicolumn{3}{|l|}{ Men } & \multicolumn{3}{|l|}{ Women } \\
\hline & $\begin{array}{l}\text { Heterosexual ( } n \\
=1662)\end{array}$ & $\begin{array}{l}\text { Gay or } \\
\text { Lesbian }(n= \\
\text { 334) }\end{array}$ & $\begin{array}{l}\text { Bisexual }(n \\
=141)\end{array}$ & $\begin{array}{l}\text { Heterosexual ( } n \\
=1652)\end{array}$ & $\begin{array}{l}\text { Gay or } \\
\text { Lesbian }(n= \\
\text { 199) }\end{array}$ & $\begin{array}{l}\text { Bisexual }(n \\
=337)\end{array}$ \\
\hline \multicolumn{7}{|l|}{ Age, no. (\%) } \\
\hline $18-29$ years & $378(22.7)$ & $84(25.0)$ & $50(35.4)$ & $320(19.4)$ & $50(25.2)$ & $159(47.2)$ \\
\hline $30-44$ years & $424(25.5)$ & $97(29.1)$ & $36(25.8)$ & $403(24.4)$ & $39(19.8)$ & $93(27.7)$ \\
\hline $45-59$ years & $448(27.0)$ & $113(33.9)$ & $33(23.5)$ & $475(28.7)$ & $72(36.3)$ & $65(19.4)$ \\
\hline$\geq 60$ years & $412(24.8)$ & $40(12.0)$ & $22(15.3)$ & $454(27.5)$ & $37(18.8)$ & $19(5.7)$ \\
\hline \multicolumn{7}{|l|}{ Education level, no. (\%) } \\
\hline Less than high school & $203(12.2)$ & $31(9.1)$ & $12(8.6)$ & $170(10.3)$ & $10(5.1)$ & $29(8.5)$ \\
\hline High school & $509(30.7)$ & $54(16.2)$ & $37(26.1)$ & $489(29.6)$ & $31(15.3)$ & $88(26.0)$ \\
\hline Some college & $465(28.0)$ & $99(29.6)$ & $54(38.6)$ & $502(30.4)$ & $70(35.0)$ & 131 (38.9) \\
\hline Bachelor's degree or higher & $485(29.2)$ & $151(45.0)$ & $38(26.7)$ & $492(29.8)$ & $89(44.5)$ & $89(26.5)$ \\
\hline \multicolumn{7}{|l|}{ Race/ethnicity, no. (\%) } \\
\hline Black, non-Hispanic & $179(10.8)$ & $34(10.2)$ & $13(9.4)$ & $192(11.6)$ & $25(12.4)$ & $43(12.8)$ \\
\hline White, non-Hispanic & $1134(68.3)$ & $221(66.0)$ & $106(75.1)$ & $1150(69.6)$ & $140(70.3)$ & $228(67.7)$ \\
\hline 2 or more races, non-Hispanic & $25(1.5)$ & $15(4.4)$ & $8(5.5)$ & $31(1.9)$ & $6(3.2)$ & $15(4.3)$ \\
\hline Other, non-Hispanic & $92(5.5)$ & $15(4.5)$ & $4(3.0)$ & $81(4.9)$ & $1(0.6)$ & $4(1.1)$ \\
\hline Hispanic & $231(13.9)$ & $50(15.0)$ & $10(7.1)$ & $198(12.0)$ & $27(13.6)$ & $47(14.0)$ \\
\hline \multicolumn{7}{|l|}{ Annual household income, no. (\%) } \\
\hline$<\$ 25,000$ & $279(16.8)$ & $86(25.6)$ & $40(28.1)$ & $328(19.8)$ & $37(18.5)$ & $106(31.6)$ \\
\hline$\$ 25,000-\$ 49,999$ & $374(22.5)$ & $77(23.0)$ & $36(25.5)$ & $395(23.9)$ & $43(21.5)$ & $100(29.7)$ \\
\hline$\$ 50,000-\$ 74,999$ & $336(20.2)$ & $43(12.8)$ & $25(17.7)$ & $309(18.7)$ & $42(21.0)$ & $43(12.8)$ \\
\hline$\$ 75,000-\$ 99,999$ & $231(13.9)$ & $51(15.3)$ & $16(11.4)$ & $279(16.9)$ & $42(21.0)$ & $39(11.6)$ \\
\hline$\geq \$ 100,000$ & $442(26.6)$ & $78(23.3)$ & $24(17.3)$ & $341(20.6)$ & $36(18.0)$ & $48(14.3)$ \\
\hline \multicolumn{7}{|l|}{ Current employment status, no. (\%) } \\
\hline Working & $1021(61.5)$ & $220(65.8)$ & $82(58.2)$ & $806(48.8)$ & $138(69.4)$ & $206(61.1)$ \\
\hline Not working & $356(21.3)$ & $85(25.5)$ & $42(29.9)$ & $518(31.4)$ & $55(18.6)$ & $126(37.5)$ \\
\hline Retired & $285(17.1)$ & $29(8.8)$ & 17 (11.9) & $329(19.9)$ & $24(12.1)$ & $5(1.5)$ \\
\hline \multicolumn{7}{|l|}{ Current relationship status, no. (\%) } \\
\hline Married & $956(57.5)$ & $28(8.4)$ & $49(34.7)$ & $840(51.1)$ & $44(21.9)$ & $105(31.1)$ \\
\hline $\begin{array}{l}\text { In a civil union or domestic } \\
\text { partnership }\end{array}$ & $16(0.9)$ & $17(5.2)$ & $1(0.9)$ & $6(0.4)$ & $16(8.1)$ & $9(2.7)$ \\
\hline $\begin{array}{l}\text { Living with a partner but not married } \\
\text { or in a civil union or domestic } \\
\text { partnership }\end{array}$ & $131(7.9)$ & $89(26.7)$ & $10(7.2)$ & $154(9.4)$ & $54(27.1)$ & $55(16.3)$ \\
\hline $\begin{array}{l}\text { In a relationship but not living } \\
\text { together }\end{array}$ & 109 (6.6) & $41(12.2)$ & $16(11.5)$ & $127(7.7)$ & $28(14.1)$ & $52(15.3)$ \\
\hline Single but dating 1 or more people & $75(4.5)$ & $18(5.3)$ & $3(2.1)$ & $79(4.8)$ & $14(7.3)$ & $23(6.8)$ \\
\hline Single and not dating & $346(20.8)$ & $140(42.0)$ & $59(42.2)$ & $358(21.8)$ & $41(20.7)$ & $83(24.7)$ \\
\hline Other & $29(1.7)$ & $1(0.2)$ & $2(1.3)$ & $79(4.8)$ & $2(0.9)$ & $11(3.2)$ \\
\hline
\end{tabular}

Table 2 Survey Responses Expressed as Proportion (95\% CI) by Self-reported Gender and Sexual Orientation $(n=4325)$

\begin{tabular}{|c|c|c|c|c|c|c|}
\hline \multirow[t]{2}{*}{ Question } & \multicolumn{3}{|l|}{ Men } & \multicolumn{3}{|l|}{ Women } \\
\hline & $\begin{array}{l}\text { Heterosexual } \\
(n=1662)\end{array}$ & $\begin{array}{l}\text { Gay or Lesbian } \\
(n=334)\end{array}$ & $\begin{array}{l}\text { Bisexual } \\
(n=141)\end{array}$ & $\begin{array}{l}\text { Heterosexual } \\
(n=1652)\end{array}$ & $\begin{array}{l}\text { Gay or Lesbian } \\
(n=199)\end{array}$ & $\begin{array}{l}\text { Bisexual } \\
(n=337)\end{array}$ \\
\hline \multicolumn{7}{|c|}{ Regular doctor or health care providers knows that person is (gay/lesbian/bisexual) } \\
\hline Yes, have talked about it & - & $54.2(47.3,61.0)$ & $14.7(6.8,22.6)$ & - & $53.3(45.0,61.7)$ & $17.2(11.2,23.2)$ \\
\hline $\begin{array}{l}\text { Yes, I think so, but have } \\
\text { not discussed it }\end{array}$ & - & $15.5(10.6,20.4)$ & $9.5(3.1,15.9)$ & - & $27.0(19.6,34.5)$ & $7.3(4.3,10.3)$ \\
\hline No, I don't think so & - & $22.4(16.3,28.4)$ & $30.1(19.7,40.4)$ & - & $11.7(7.2,16.1)$ & $39.1(31.7,46.5)$ \\
\hline Definitely not & - & $8.0(3.8,12.2)$ & $45.7(34.0,57.4)$ & - & $7.9(2.9,13.0)$ & $36.4(29.1,43.7)$ \\
\hline $\begin{array}{l}\text { Talked to a provider about } \\
\text { sexual problem(s) or } \\
\text { concern(s) in past } 12 \\
\text { months }\end{array}$ & $11.5(9.7,13.4)$ & $13.5(9.4,17.6)$ & $14.7(6.7,22.7)$ & $10.1(8.1,12.1)$ & $8.0(3.7,12.3)$ & $15.1(10.0,20.2)$ \\
\hline $\begin{array}{l}\text { Reported persistent sexual } \\
\text { problem(s) or concern(s) in } \\
\text { past } 12 \text { months }\end{array}$ & $22.5(20.1,24.9)$ & $29.6(23.5,35.7)$ & $34.6(24.0,45.2)$ & $23.2(20.5,25.9)$ & $26.0(18.8,33.4)$ & $42.3(35.2,49.3)$ \\
\hline $\begin{array}{l}\text { Of those who reported } \\
\text { persistent problem, talked } \\
\text { to a provider }\end{array}$ & $31.1(25.5,36.7)$ & $29.6(19.4,39.8)$ & $37.3(18.6,56.0)$ & $19.6(14.6,24.7)$ & $18.4(5.9,31.0)$ & $21.5(12.8,30.2)$ \\
\hline $\begin{array}{l}\text { Ever received care or } \\
\text { treatment from a provider } \\
\text { for a sexual problem or } \\
\text { concern }\end{array}$ & $16.6(14.4,18.7)$ & $21.7(16.6,26.8)$ & $22.6(14.6,30.6)$ & $14.1(11.8,16.4)$ & $6.2(2.6,9.8)$ & $17.5(12.4,22.6)$ \\
\hline
\end{tabular}




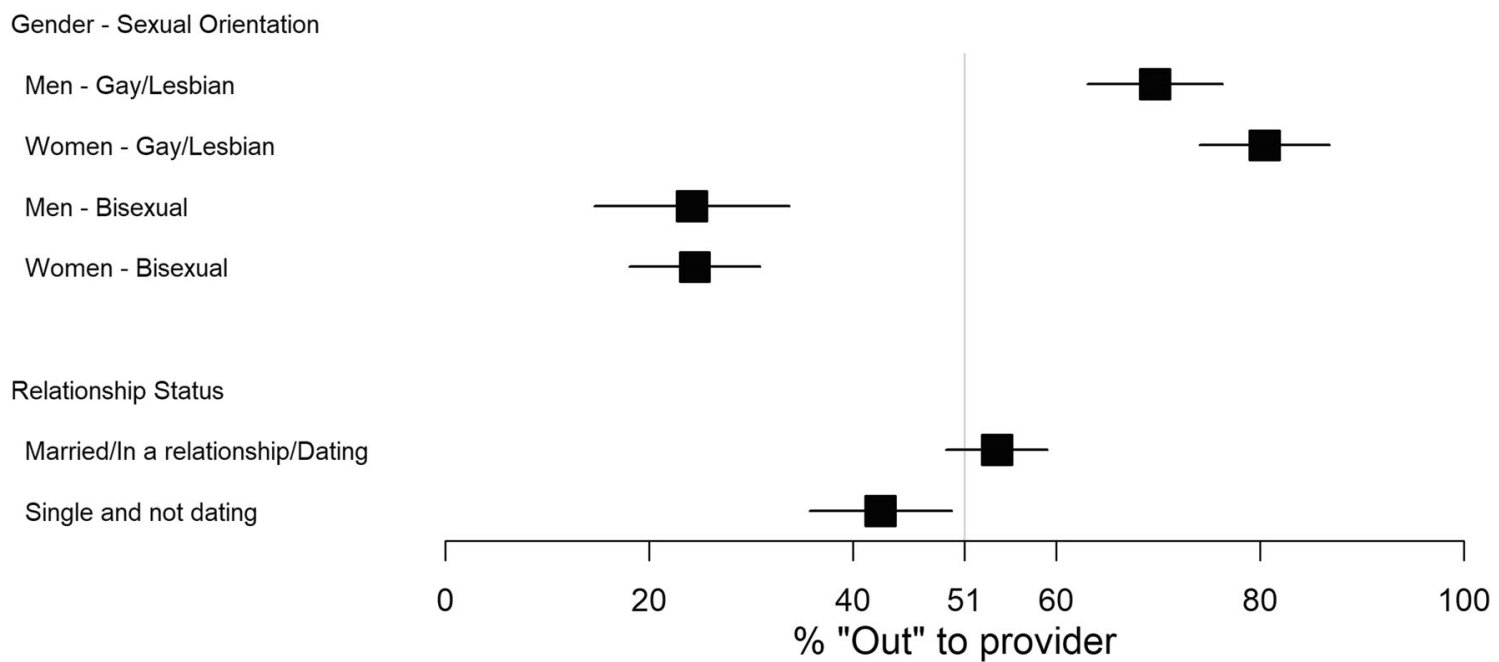

Figure 1 Proportions with 95\% CIs of US adults reporting being "out" to their doctor or health care provider by gender/sexual orientation and relationship status $(n=1011)$.

\section{Patient-Provider Communication About Sexual Problems}

A minority of US adults had discussed a sexual problem or concern with a doctor or health care provider in the past 12 months. The proportions of men and women who had discussed sexual problems with a clinician in the previous year ranged from 8 to $15 \%$ (Table 2). The differences by gender/sexual orientation were not statistically significant; all of the confidence intervals overlapped. The largest difference was between lesbian women (8\%) and bisexual women $(15 \%)$ and bisexual men (15\%).

We examined whether there were differences among sexual minority adults regarding having ever talked to a doctor or health care provider about a sexual problem or concern. Overall, $22 \%$ of sexual minority adults had ever talked to a provider about a sexual problem (Fig. 2). The differences were small by gender/sexual orientation and the confidence intervals overlapped. However, there were notable differences in having ever talked to a provider based on whether the person reported being "out" to their regular provider. Among those who were "out," $30 \%$ had talked to a provider about a sexual problem, while among those who were not "out," $17 \%$ had.

\section{Health Care in the Context of Persistent Sexual Problems}

The proportions of persons who reported a persistent sexual problem or concern in the past year ranged from $23 \%$ among heterosexual men and women to $42 \%$ among bisexual women (Table 2); however, only a minority of persons reporting a problem discussed it with a clinician (ranging from $18 \%$ for lesbian women to $37 \%$ for bisexual men). In general, a higher proportion of men had talked to a clinician compared with women. Heterosexual men were significantly more likely to have done so compared with heterosexual women (31\% vs $20 \%$ ). The patterns were similar comparing sexual minority men and women, though the confidence intervals overlapped, likely due to smaller sample sizes.

A significantly smaller proportion of lesbian women compared with other groups had ever received care or treatment from a provider for a sexual problem or concern, just $6 \%$. For the other groups, the proportion was at least two times higher: $14 \%$ of heterosexual women and $17 \%$ of heterosexual men, and as much as three to four times higher among other sexual minority adults (bisexual women $18 \%$, gay men $22 \%$, and bisexual men 23\%).

\section{DISCUSSION}

There are significant unmet needs among US adults with regard to patient-provider communication about sexual problems or concerns. Over $1 / 5$ th of participants reported at least one persistent sexual problem or concern over the past year, but the majority of these had not discussed any concerns with a health care provider. This was true for both men and women and for heterosexual as well as sexual minority adults. Improving patient-provider communication about sexual problems is key to addressing them. Valid screening methods ${ }^{18}$ and patients' preferences for history taking ${ }^{20}$ are important considerations in efforts to improve routine screening for sexual problems, as is improving medical student education following best practices for sexual history taking. ${ }^{21}$ Notably, while a similar proportion of lesbian women reported persistent problems compared with other groups, fewer had talked to a clinician, and only $6 \%$ reported having ever received care or treatment for a sexual problem or concern. Our data do not provide insight into reasons for this finding, and it should be explored in future research.

More men than women had discussed a sexual problem or concern with a health care provider. This may be due to the successful marketing of phosphodiesterase type 5 (PDE-5) 


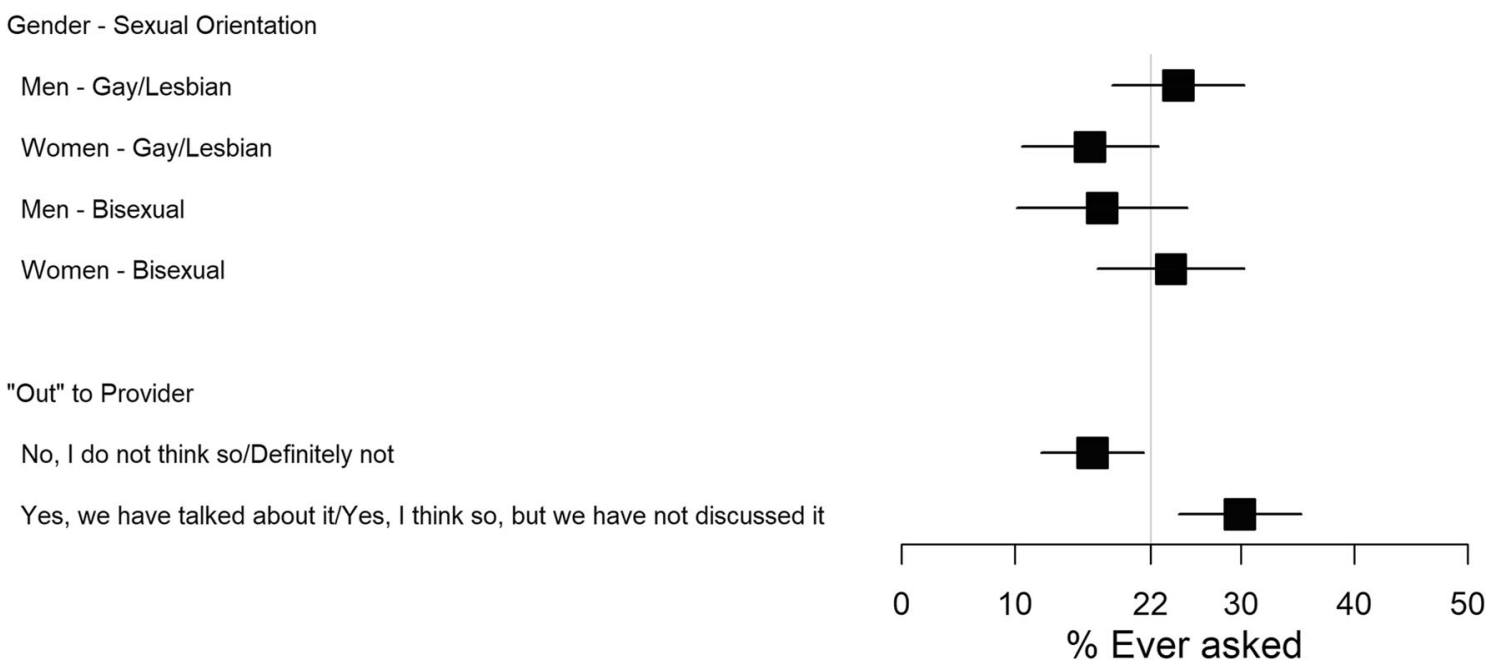

Figure 2 Proportions with $95 \%$ CIs of US adults reporting they ever asked a doctor or health care provider about a sexual problem or concern by gender/sexual orientation and being "out" to their regular provider $(n=1011)$.

inhibitors for treating erectile dysfunction; when physicians are aware of a pharmacological treatment, it may be easier to discuss and offer to patients. Yet experts have recommended ${ }^{3}$ that the best treatment strategy for both men and women is a concurrent multidisciplinary approach, ${ }^{22}$ integrating medical and psychological treatments. Regarding the latter, psychological approaches should be offered including cognitive behavioral therapy and mindfulness. Simultaneously, pharmacological options can be offered when available, such as estrogens or an estrogen agonist/antagonist for women experiencing pain with intercourse, a norepinephrine-dopamine disinhibitor for low sexual desire in women, testosterone for low sexual desire in men, and PDE-5 inhibitors or prostaglandin E1 for men with erectile dysfunction.

Among sexual minority adults, disclosure of sexual orientation was clearly associated with patient-provider communication about sexual concerns. With cross-sectional data, we could not determine the direction of this association. Being "out" to a clinician may facilitate discussions about sexual concerns; conversely, discussions about sexual concerns may facilitate disclosure of sexual orientation. Previous qualitative exploration of disclosure suggested that patients provide this information casually and indirectly. ${ }^{23}$ For example, a gay male patient may disclose to his provider by using the malegendered name of his sexual partner as he is talking about sexual activity. In our sample, gay and lesbian participants were much more likely than bisexual participants to be "out" to their usual provider. Previous research suggests that nondisclosure among bisexual men is often used as a stigma management strategy. ${ }^{24}$ In general, physician discomfort with human sexuality and its role in patient non-disclosure has been underexplored, though it is likely that physicians and other health care providers are inadequately prepared to navigate patient disclosure and/or the unique clinical considerations of sexual minority patients. In a report from $2011,44 \%$ of medical schools rated their lesbian, gay, bisexual, and transgender- related content as "fair," and nearly $1 / 3$ of medical schools reported zero hours focused on training. ${ }^{25}$

Our data suggest that there is a nontrivial portion of sexual minority patients who are not "out" to their physicians, which could create difficulties for effective communication about sexual health. Qualitative interviews with general practitioners in the UK revealed physician discomfort discussing sexual health with lesbian and gay patients, supporting the need for training on this topic. ${ }^{26}$ A recent report from the Association of American Medical Colleges addresses these challenges by identifying physician competencies and institutional and curricular standards to improve the clinical experiences and care of sexual minority patients. ${ }^{27}$ Physicians who use inclusive, normalizing, and behaviorally focused questions such as "are you sexually active?" followed by a question such as "are you having sex with men, women, or both?" are highly effective in working with sexual minority patients. ${ }^{28}$ Emerging clinical best practice recommendations aim to also be inclusive of those with diverse gender identities, and suggest using questions such as "when you are sexually active what parts of your body do you use?" and "how do your partner(s) identify their gender [and] sexual orientation?"29 Such lines of questioning provide a validating message of normalcy that may increase trust and the likelihood that a patient would feel comfortable disclosing important details about their sexual behaviors as well as any sexual problems or concerns. In addition, frank, relevant, and non-judgmental questions about sexual acts (i.e., "Have you engaged in anal sex? If so, were you the receptive or penetrative partner?") are likely to make sexual minority patients more comfortable, and thus more forthcoming with important details about sexual behaviors that carry implications about health risks. For example, in one study, a primary care physician's knowledge of their gay or bisexual male patients' sexual orientation informed their preventative health recommendations. Known gay or bisexual men were referred for HIV testing at a rate of $59 \%$ versus only $13 \%$ of unknown 
gay or bisexual men, and known gay or bisexual men were referred for hepatitis $\mathrm{A}$ and $\mathrm{B}$ vaccination at a rate of $32 \%$ versus $16 \%$ of unknown gay or bisexual men. ${ }^{30}$

Our study has important limitations. Chiefly, we do not know the content of communication about sexual problems or concerns and whether it was related to sexual dysfunction, sexually transmitted infections, prevention, or something else. Second, we only surveyed English-speaking individuals. We suspect that patients who additionally face language barriers would find these discussions even more challenging. Third, our data do not permit examination of the potential impact on communication of the heath care provider's sexual orientation. Fourth, there may be non-response bias. For both samples, we targeted a particular sample size rather than a particular response rate, and as a result, our response rates did not reach $60 \%$. That said, we used GfK's KnowledgePanel for data collection because of its representativeness of the Englishspeaking, noninstitutionalized US adult population. This represents an important strength, and ours is the first study to our knowledge to compare patient-provider communication about sexual problems or concerns by sex and sexual orientation in a large, national sample. Finally, although our sample was large overall, it was not large enough to permit more nuanced analyses accounting for gender, sexual orientation, age, sexual dysfunction, and the interactions among these variables.

\section{Conclusions}

Sexual health concerns are common among US adult women and men, yet few people, regardless of their sexual orientation, speak with health care providers about such concerns. Unmet needs appeared to be higher among women compared with men. Self-identified gay, lesbian, and bisexual patients who reported being "out" to their usual provider were more likely to have discussed sexual problems or concerns with a clinician than those who were not "out." Patient-centered care for patients with sexual concerns will require greater efforts to educate providers on how to communicate about sexual health using inclusive language in order to address patients' concerns in an appropriate and personalized way.

Corresponding Author: Kathryn E. Flynn, PhD; Medical College of Wisconsin, 9200 W. Wisconsin Ave., Milwaukee, WI 53226, USA (e-mail: kflynn@mcw.edu).

Funding Information This study was supported by grant U01AR052186 from the National Institute of Arthritis and Musculoskeletal and Skin Diseases and the Research and Education Program Fund, a component of the Advancing a Healthier Wisconsin endowment at the Medical College of Wisconsin. Additional support to Dr. Rachel Cusatis was from a National Research Service Award under Grant [T32 HP10030].

\section{Compliance with Ethical Standards:}

The institutional review boards of the Duke University Health System and the Medical College of Wisconsin approved the studies, and participants provided consent online.
Conflict of Interest: K.W. has served as a consultant to Regeneron, Strategic Science and Technologies for work performed outside of the current study. The other authors report no potential conflicts of interest.

Disclaimer: The content is solely the responsibility of the authors and does not necessarily represent the official views of the National Institute of Arthritis and Musculoskeletal and Skin Diseases, the National Institutes of Health, or the Advancing a Healthier Wisconsin endowment.

\section{REFERENCES}

1. Flynn KE, Lin L, Bruner DW, et al. Sexual Satisfaction and the Importance of Sexual Health to Quality of Life Throughout the Life Course of U.S. Adults. J Sex Med 2016; 13(11):1642-1650.

2. Laumann EO, Nicolosi A, Glasser DB, et al. Sexual problems among women and men aged 40-80 y: prevalence and correlates identified in the Global Study of Sexual Attitudes and Behaviors. Int J Impot Res 2005;17(1):39-57.

3. Wincze JP, Weisberg RB. Sexual dysfunction: A guide for assessment and treatment. 3rd ed. New York: Guilford Publications; 2015.

4. Kingsberg SA, Althof S, Simon JA, et al. Female sexual dysfunctionmedical and psychological treatments, committee 14. J Sex Med 2017;14(12):1463-1491.

5. Hatzimouratidis K, Salonia A, Adaikan G, et al. Pharmacotherapy for erectile dysfunction: recommendations from the fourth International Consultation for Sexual Medicine (ICSM 2015). J Sex Med 2016;13(4):465-488.

6. Khera M, Adaikan $\mathbf{G}$, Buvat $\mathbf{J}$, et al. Diagnosis and treatment of testosterone deficiency: recommendations from the fourth International Consultation for Sexual Medicine (ICSM 2015). J Sex Med 2016;13(12):1787-1804.

7. Gott M, Galena E, Hinchliff S, Elford H. "Opening a can of worms": GP and practice nurse barriers to talking about sexual health in primary care. Fam Pract 2004;21(5):528-536.

8. Reese JB, Sorice K, Beach MC, et al. Patient-provider communication about sexual concerns in cancer: a systematic review. J Cancer Surviv. 2016; 11(2):175-188.

9. Flynn KE, Reese JB, Jeffery DD, et al. Patient experiences with communication about sex during and after treatment for cancer. Psychooncology 2012;21(6):594-601.

10. Lindau ST, Abramsohn E, Bueno $\mathbf{H}$, et al. Sexual Activity and Function in the Year After an Acute Myocardial Infarction Among Younger Women and Men in the United States and Spain. JAMA Cardiol 2016;1(7):754-764.

11. Bergeron CD, Goltz HH, Szucs LE, et al. Exploring sexual behaviors and health communication among older women. Health Care Women Int 2017;38(12):1356-1372.

12. Politi MC, Clark MA, Armstrong G, McGarry KA, Sciamanna CN. Patient-provider communication about sexual health among unmarried middle-aged and older women. J Gen Intern Med 2009;24(4):511-516.

13. Rose D, Ussher JM, Perz J. Let's talk about gay sex: gay and bisexual men's sexual communication with healthcare professionals after prostate cancer. Eur J Cancer Care 2017;26(1):e12469.

14. Kuyper L, Vanwesenbeeck I. Examining sexual health differences between lesbian, gay, bisexual, and heterosexual adults: the role of sociodemographics, sexual behavior characteristics, and minority stress. J Sex Res 2011;48(2-3):263-274.

15. Brooks H, Llewellyn CD, Nadarzynski T, et al. Sexual orientation disclosure in health care: a systematic review. $\mathrm{Br} \mathrm{J}$ Gen Pract 2018;68(668):e187-e196.

16. Flynn KE, Lin L, Weinfurt KP. Sexual function and satisfaction among heterosexual and sexual minority U.S. adults: A cross-sectional survey. PLoS One 2017;12(4):e0174981.

17. Ipsos KnowledgePanel. KnowledgePanel Design Summary. https://www. ipsos.com/en-us/solution/knowledgepanel (Accessed May 8 2019).

18. Flynn KE, Lindau ST, Lin L, et al. Development and validation of a single-item screener for self-reporting sexual problems in U.S. adults. J Gen Intern Med 2015;30(10):1468-1475.

19. Cumming G. Understanding the new statistics: Effect sizes, confidence intervals, and meta-analysis. New York: Routledge; 2011. 
20. Clark RD, Williams AA. Patient preferences in discussing sexual dysfunctions in primary care. Fam Med 2014;46(2):124-128.

21. Rubin ES, Rullo J, Tsai $\mathbf{P}$, et al. Best practices in North American preclinical medical education in sexual history taking: Consensus from the summits in medical education in sexual health. J Sex Med 2018;15(10):1414-1425.

22. Binik YM, Meana M. The future of sex therapy: specialization or marginalization? Arch Sex Behav 2009;38(6):1016-1027.

23. Venetis MK, Meyerson BE, Friley LB, Gillespie A, Ohmit A, Shields CG. Characterizing sexual orientation disclosure to health care providers: Lesbian, gay, and bisexual perspectives. Health Commun 2017;32(5):578-586.

24. Schrimshaw EW, Downing MJ, Jr., Cohn DJ. Reasons for NonDisclosure of Sexual Orientation Among Behaviorally Bisexual Men: Non-Disclosure as Stigma Management. Arch Sex Behav 2018;47(1):219-233.

25. Obedin-Maliver J, Goldsmith ES, Stewart L, et al. Lesbian, gay, bisexual, and transgender-related content in undergraduate medical education. JAMA 2011;306(9):971-977.

26. Hinchliff S, Gott M, Galena E. 'I daresay I might find it embarrassing' general practitioners' perspectives on discussing sexual health issues with lesbian and gay patients. Health Soc Care Community 2005;13(4):345-353.

27. Association of American Medical Colleges. Implementing curricular and institutional climate changes to improve health care for individuals who are LGBT, gender nonconforming, or born with DSD: A resource for medical educators. Washington, DC: Association of American Medical CollegesAssociation of American Medical Colleges; 2014.

28. Fuzzell L, Fedesco HN, Alexander SC, Fortenberry JD, Shields CG. "I just think that doctors need to ask more questions": Sexual minority and majority adolescents' experiences talking about sexuality with healthcare providers. Patient Educ Couns 2016;99(9):1467-1472.

29. McNamara MC, Ng $\mathbf{H}$. Best practices in LGBT care: A guide for primary care physicians. Cleve Clin J Med 2016;83(7):531-541.

30. Petroll AE, Mosack KE. Physician awareness of sexual orientation and preventive health recommendations to men who have sex with men. Sex Transm Dis 2011;38(1):63-67.

Publisher's Note Springer Nature remains neutral with regard to jurisdictional claims in published maps and institutional affiliations. 